\title{
TOCILIZUMAB THERAPY TO LOWER MORTALITY IN COVID-19 PATIENTS: A META-ANALYSIS
}

\author{
Winei Handriani
}

\author{
Masters Program in Public Health, Universitas Sebelas Maret
}

\begin{abstract}
Background: IL-6, one of pro-inflammatory cytokine, plays a key role in the clinical manifestations of COVID-19 disease and represents a predictive marker of fatal outcome. Several drugs targeting the IL-6 pathway have been attempted, including tocilizumab (TCZ). However, data supporting the use of Tocilizumab (TCZ) in COVID-19 are contrasting and inconclusive. This study aimed to evaluate the effect of Tocilizumab therapy to lower mortality in COVID-19 patients.

Subjects and Method: A systematic review and meta analysis was conducted using the Pubmed, Google Scholar, and Science Direct databases, published from 2020 to 2021. Eligibility criteria were defined using the PICO model as follows, (1) population: COVID-19 patients, (2) intervention: tocilizumab therapy, (3) comparison: non tocilizumab therapy, and (4) outcome: mortality. The following search terms were used: Tocilizumab" AND "COVID-19" AND "Mortality" AND "adjective hazard ratio". The inclusion criteria were English full-text, cohort study, and reported adjusted Hazard Ratio (aHR). The systematic review was carried out according to the PRISMA guidelines. Data analyses were performed using RevMan 5.3.

Results: 6 studies from United States, Italy, France, and Spain were involved for meta-analysis. This study showed that tocilizumab therapy reduced mortality in COVID-19 patients $(\mathrm{aHR}=0.44 ; 95 \% \mathrm{CI}=0.36$ to $0.55 ; \mathrm{p}<0.001)$.
\end{abstract}

Conclusion: Tocilizumab therapy reduces mortality in COVID-19 patients.

Keywords: Tocilizumab, mortality, COVID-19.

\section{Correspondence:}

Winei Handriani. Masters Program in Public Health, Universitas Sebelas Maret. Jl. Ir. Sutami 36A, Surakarta 57126, Central Java. Email: wineihandrianio2@gmail.com. Moblie: 083150000253. 